\title{
RURAL ROADS AS BARRIERS TO THE MOVEMENTS OF SMALL MAMMALS
}

\author{
MACPHERSON, D. - MACPHERSON, J.L. ${ }^{1} *$ - MORRIS, P. \\ ${ }^{1}$ Royal Holloway University of London \\ Egham Hill, Egham, Surrey TW20 OEX, UK. \\ (phone: $+44(0) 1784443772$ fax: $+44(0) 1784434326)$ \\ *Corresponding author \\ e-mail: jennymacpherson@vwt.org.uk \\ (Received $28^{\text {th }}$ February 2011; accepted $27^{\text {th }}$ May 2011)
}

\begin{abstract}
Over the last 50 years increasing fragmentation of habitats has occurred due to road building. Fragmenting a large population into smaller ones can have a negative effect on population demography. In England much small mammal habitat occurs in suburban and rural areas where the majority of roads are either single track or two lanes, and traffic density is light. This study investigated the effect of minor roads on the movements of two small mammals, the wood mouse (Apodemus sylvaticus) and bank vole (Myodes glareolus). Capture-Mark-Recapture was used to study movements beside and across rural roads of two different widths. The results suggest that even small roads less than 6metres wide, with relatively little traffic, do act as partial barriers for these small mammals, reducing their movement between habitats on either side of the road. It is evident that island populations are being created as a result of road construction, even access roads within nature reserves.
\end{abstract}

Keywords: habitat fragmentation, barrier, wood mouse, bank vole, animal movements

\section{Introduction}

Fragmenting a large population into smaller units has a negative effect on population demography (Fischer and Lindenmayer, 2000). The degree to which this fragmentation affects animal survival depends upon both the size of the fragments and the degree of isolation imposed on their inhabitants. Habitat fragmentation may deplete a large and varied gene pool, increasing the chances of deleterious mutations becoming fixed within the populations and reducing fecundity due to inbreeding depression. Balanced immigration and emigration are likely to be compromised, increasing the risk of local extinctions. Vulnerability to extinction for a given population is negatively correlated to the size of that population (Goodman, 1987; Lande, 1993), therefore with smaller habitat fragments and hence smaller populations, the degree of isolation is crucial. The concept of metapopulations suggests that, if there are no barriers between population fragments, the risk of extinction is much reduced (Hanski, 1999). If however the intervening space between fragments acts as a barrier to movement the risk of extinction is enhanced.

Over the last 50 years increasing fragmentation of habitats has occurred due to development and road building (Gerlach and Musolf, 2000). In many parts of Europe roads have created a fine network of "islands", averaging less than $3.2 \mathrm{~km}^{2}$ in size (Mader, 1984). In 1985 the UK had 365000km of roads, by 2009 this had risen to approximately $394000 \mathrm{~km}$, of which $87 \%$ are classed as 'minor' (B and C) roads (Dept. for Transport, 2011). As more roads are constructed, so more habitats become fragmented into smaller patches, many of which consist entirely of roadside verge. Although verges offer wildlife habitats (Adams and Geiss, 1983; Way, 1977), they are 
potentially isolated islands if the road itself forms a barrier to movement. For small mammals any movement across roads potentially places an individual in danger not only from traffic, but also from predators. Sikorski and Bernstein (1984) showed that parts of a population inhabiting territories on either side of a road differed in certain non-metric dental and cranial features. Since then a number of studies of genetic differentiation have found that roads have a negative effect on genetic diversity in many animal species (Holderegger and Di Giulio, 2010). This seems to indicate that roads act as total barriers for some small mammals, creating island populations and increased extinction risk.

Oxley et al. (1974) suggested that small forest mammals were reluctant to venture on to road surfaces where the distance between forest margins exceeded 20 metres. Mader (1984) found that none of the 121 yellow necked mice (Apodemus flavicollis) he had marked crossed a highway 6m wide. However Bakowski and Koziakiewicz (1988) showed that a $5 \mathrm{~m}$ wide gravel forest road, whilst not a barrier to A. flavicollis, did act as a barrier for Clethrionomys glareolus. Whatever the reason for not crossing a road, reduced interaction between populations may have far-reaching effects, such as reduction or even loss of gene flow. Roads may also disrupt social organisation: Mansergh and Scotts (1989) demonstrated that survival rates of the mountain pygmypossum (Burramys parvus) had been reduced by road construction. The road was found to act as a barrier to dispersal of males; reducing the over-winter survival rate of females. Over time this could have led to the extinction of this rare Australian mammal, which had previously only been known from fossils. Two tunnels were built under the road at strategic points, allowing the social structure to resume its normal pattern and the over winter survival rate of the females recovered.

In England many of the habitats suitable for small mammals are found in suburban and rural areas where the majority of roads are either single track or two lanes with a hard surface, and traffic density for most of the time is light. It is important for reasons mentioned above that we should know whether we are increasingly creating isolated island populations by building more roads. This applies not only to these public roads but also access roads within forestry areas and nature reserves. It is therefore important to understand the degree of isolation that roads impose upon the inhabitants of habitat fragments. The present study therefore investigated the extent to which even small roads (DoT classification B \& C) compromise animal movements, implying that wider roads (and those with a physical barrier along their centre or margins) act as increasingly severe obstructions.

\section{Methods}

The wood mouse, Apodemus sylvaticus, and the bank vole, Myodes glareolus, were chosen as study species due to their frequent occurrence in roadside verges, and therefore their potential vulnerability to isolation effects from roads. Two study sites were chosen with road widths of $6 \mathrm{~m}$ and $2 \mathrm{~m}$, both with verges of equal or greater width than the road itself and with both study species at similar population densities indicated by approximately 10 captures per 100 trap nights effort. In addition both sites had similar amounts and types of vegetation on either side of the road, and had minimal disturbance by pedestrians and vehicles

Site A was in Denham, Buckinghamshire (51.560620N, $-0.502567 \mathrm{~W})$. This was a $6 \mathrm{~m}$ wide road with a tarmacadam surface. The verges either side were approximately 
eight metres in width and bordered by pasture land. The fields on one side were separated from the verge by a continuous wire fence and on the other by a dense hawthorn hedgerow. The vegetation on both sides was similar, consisting mainly of Arrhenatherum elatus and Rubus fruticosa. Traffic was mainly between 08.00-10.00 and 17.00-19.00, with approximately 20 vehicles per hour during these periods. A total of 120 Longworth traps were set in six transect lines, three on each side of the road parallel to it and $3 \mathrm{~m}$ apart. Each trap line consisted of 20 traps at $5 \mathrm{~m}$ intervals.

Site B was a 2-2.5m wide road with a similar hard surface in Langley, Berkshire $(51.523933 \mathrm{~N},-0.516744 \mathrm{~W})$. The road had verges of $3 \mathrm{~m}$ width either side, bordered by pasture land. The verges on both sides were separated from the agricultural land by a continuous wire fence. Again the vegetation either side was similar with a predominance of Hedera helix and Rubus fruticosa, but, unlike site A, both sides of the road were lined by tall trees which created a continuous canopy over the road in some places. Traffic was very light with the busiest times being 07.00-09.00and 17.00-19.00 with an average of 5 vehicles per hour during those periods. A total of 100 Longworth traps were set in four transect lines $3 \mathrm{~m}$ apart, two either side of the road and parallel with it. Each line consisted of 25 traps placed $3 \mathrm{~m}$ apart.

Trapping was carried out during June, July and August. The traps were supplied with hay as bedding material, adequate food and baited with fried bread. They were checked twice daily at 06.30 and 18.30. The Capture-Mark-Release (CMR) method was employed. Each animal captured was marked by fur clipping (Gurnell and Flowerdew 1995) and species, sex, breeding condition, weight and place of capture were all recorded. A total of 6600 trap nights effort was employed, 3600 at site A, and 3000 at site B. For the first 3240 trap nights at site A and 2700 at site B, animals were released at the point of capture, whilst for the remaining period animals captured (other than pregnant or lactating females) were translocated to the opposite side of the road to see whether they would cross the road to return to their point of capture. The null hypothesis was that there would be no significant difference between the frequency of movements across the road, compared with movements over similar distances within the verge habitats.

\section{Results}

The numbers of animals captured, marked and re-captured per 100 trap nights effort for both sites are shown in Table 1. Animals captured at both sites were predominantly adults in breeding condition ( $71 \%$ at site $\mathrm{A}$ and $69 \%$ at site B).

Table 1. Number of marked animals, captures on side 1 and 2 and catch per unit effort at Site A (3600 trap nights effort) and B (3000) trap nights effort

\begin{tabular}{l|c|c|c|c|c}
\hline & site & sex & $\begin{array}{c}\text { No. of marked } \\
\text { individuals }\end{array}$ & $\begin{array}{c}\text { No. of } \\
\text { captures }\end{array}$ & $\begin{array}{c}\text { Catch per 100 } \\
\text { TNE }\end{array}$ \\
\hline A. sylvaticus & A & Male & 33 & 238 & 6.611 \\
& A & Female & 23 & 113 & 3.138 \\
& B & Male & 23 & 197 & 6.566 \\
M. glareolus & B & Female & 19 & 109 & 3.633 \\
& A & Male & 32 & 194 & 5.388 \\
& A & female & 36 & 329 & 9.138 \\
& B & Male & 28 & 181 & 6.033 \\
& B & female & 26 & 142 & 4.730 \\
\hline
\end{tabular}


At site A this generated a total of 608 recorded movements of which 377 (62\%) were equivalent to or greater than the width of the road. Of these, 158 involved A. sylvaticus and $219 \mathrm{M}$. glareolus, with the number of recorded road crossings being 4 and 8 respectively. At site B a total of 419 movements were recorded, of which 395 (94\%) were greater than the width of the road were recorded, but there were only 12 for each species involving road crossings. Two hundred and five movements involved A sylvaticus and $214 \mathrm{M}$. glareolus, with 12 recorded road crossings for each species. All classes of movement are presented in figure 1. Thus of all the 772 movements recorded, equivalent to the road width or greater, only $36(4.7 \%)$ involved actual road crossings.
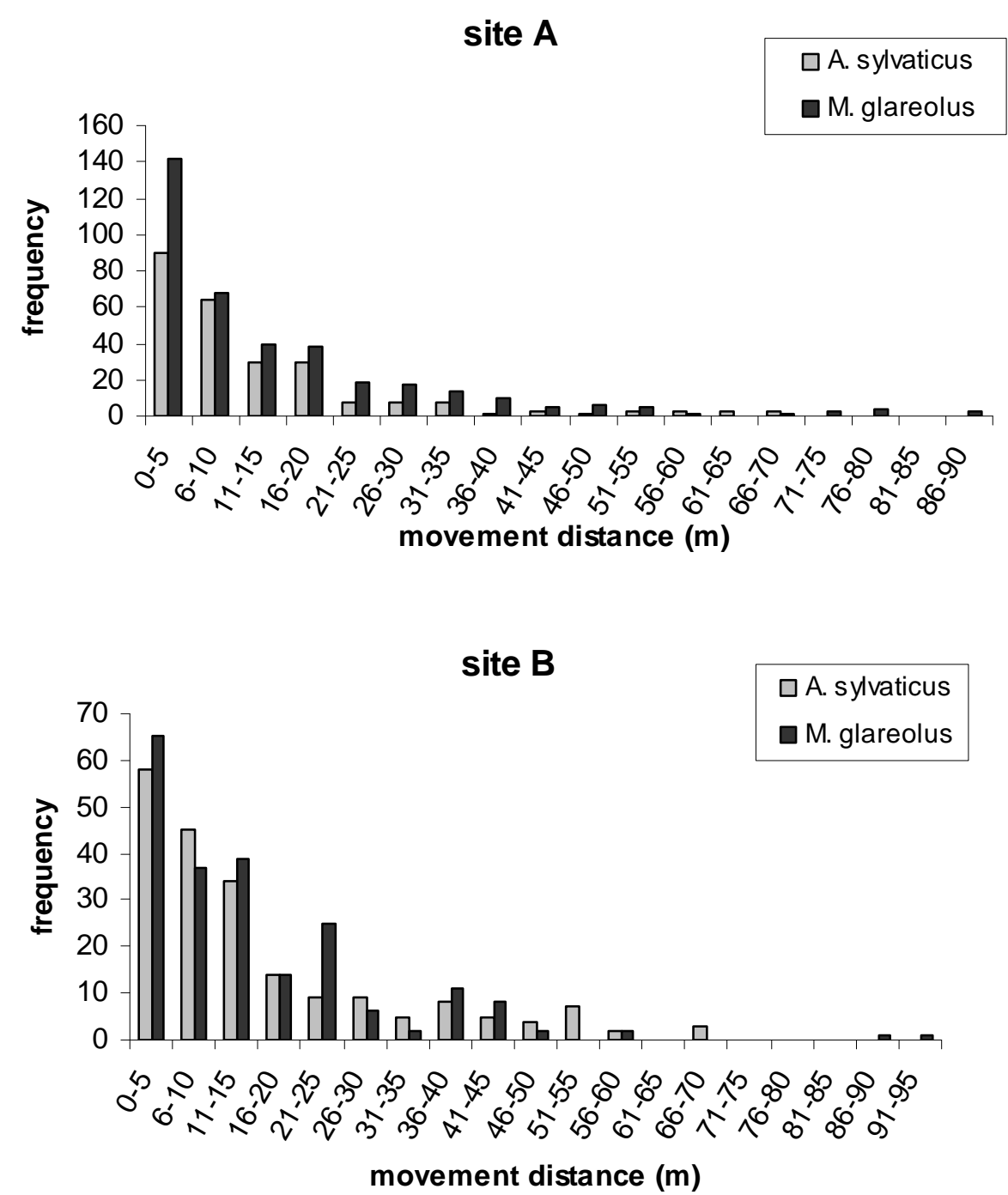

Figure 1. Frequency of movements of different distances for A. sylvaticus and $M$. glareolus at site $A$ (top) and site B (bottom)

A binomial test was used to determine whether there was a significant difference between the number of movements equal to or greater than the width of the road within 
the verge and the number of movements across the road. In all cases there was a very highly significant difference and the null hypothesis was rejected (Table 2).

Table 2. Movement data and results of binomial tests comparing numbers of recorded movements within verge and across roads

\begin{tabular}{c|l|c|c|c|c}
\hline Site & Species & $\begin{array}{c}\text { Number of } \\
\text { movements } \\
\text { within verge } \geq \\
\text { width of road }\end{array}$ & $\begin{array}{c}\text { Number of } \\
\text { movements } \\
\text { across road }\end{array}$ & Z statistic & $\begin{array}{c}\mathbf{P} \\
\text { (2 tailed) }\end{array}$ \\
\hline $\mathrm{A}$ & A. sylvaticus & 154 & 4 & 11.85 & $<0.001$ \\
$\mathrm{~B}$ & M. glareolus & 211 & 8 & 13.65 & $<0.001$ \\
& A. sylvaticus & 193 & 12 & 12.57 & $<0.001$ \\
& M. glareolus & 202 & 12 & 12.91 & $<0.001$ \\
\hline
\end{tabular}

A binomial test was then used to investigate whether the verges on either side of the roads had similar numbers of marked animals of each species. For both A. sylvaticus and $M$. glareolus at site B there was no significant difference. However for site A the results indicate that there was a highly significant difference between the numbers of $A$. sylvaticus marked in side 1 and side 2 (Table 3) suggesting that the population on side 1 was smaller than that on side 2 .

Table 3. Numbers of marked animals and results of binomial test on differences in the numbers marked on each side of the roads

\begin{tabular}{l|l|c|c|c|c}
\hline Site & Species & $\begin{array}{c}\text { Number of } \\
\text { animals marked } \\
\text { side 1 }\end{array}$ & $\begin{array}{c}\text { Number of } \\
\text { animals marked } \\
\text { side 2 }\end{array}$ & Z statistic & $\begin{array}{c}\text { P } \\
\text { (2 tailed) }\end{array}$ \\
\hline $\mathrm{A}$ & A. sylvaticus & 18 & 38 & -2.54 & 0.0111 \\
$\mathrm{~B}$ & M. glareolus & 22 & 34 & -1.47 & 0.1416 \\
& A. sylvaticus & 17 & 21 & -0.49 & 0.6265 \\
& M. glareolus & 32 & 23 & 1.08 & 0.2807 \\
\hline
\end{tabular}

We then tested the movement data to determine if there were any significant differences between species in the number of recorded movements equal to or greater than the width of the road. For site A a highly significant difference was found $(\mathrm{z}=-2.93$; 2 tailed $\mathrm{p}=0.003)$. This result, plus the highly significant difference found in the numbers of A. sylvaticus marked (Table 2) suggests that, for A. sylvaticus at site A, the verge on side 1 was unable to support a population similar in size to that of side 2 .

At site $\mathrm{B}$ the number of recorded movements equal to or greater than the width of the road was not significantly different between species $(\mathrm{Z}=-0.40 ; 2$ tailed $p=0.687)$ neither was there any difference in the numbers of marked animals found (Table 2) and, unlike site A, $50 \%$ of recorded crossings were made by A. sylvaticus. We also tested the hypothesis that there was no significant difference in the distances travelled between male and female animals within a species. The only significant difference was between male and female A. sylvaticus at site A $\left(\mathrm{U}=135, n_{1}=19, n_{2}=23, p<0.05\right)$. There was no significant difference between distances travelled by M.glareolus and A. sylvaticus at site A or site B. Movements across the road by both species are shown in Figures 2 and 3 .

It can be seen from these plots that, whilst crossings by $M$. glareolus cover the length of the trap grid at site A, those of A. sylvaticus (although only two animals were recorded crossing) are concentrated at one end, yet this species occurred in all areas of 
both trapping grids. In addition $75 \%$ of crossings recorded for $M$. glareolus were from side 2 to side 1, whilst the opposite was true for A. sylvaticus with $75 \%$ from side 1 to side 2 . Only $28.5 \%$ of animals recorded crossing the road were males (all males recorded crossing being $M$. glareolus), but these accounted for $41 \%$ of the crossings recorded this being due to only one female being recorded making multiple crossings. Of all animals recorded crossing at site A only one was sub-adult, all other animals involved were adults in breeding condition weighing $>20 \mathrm{~g}$

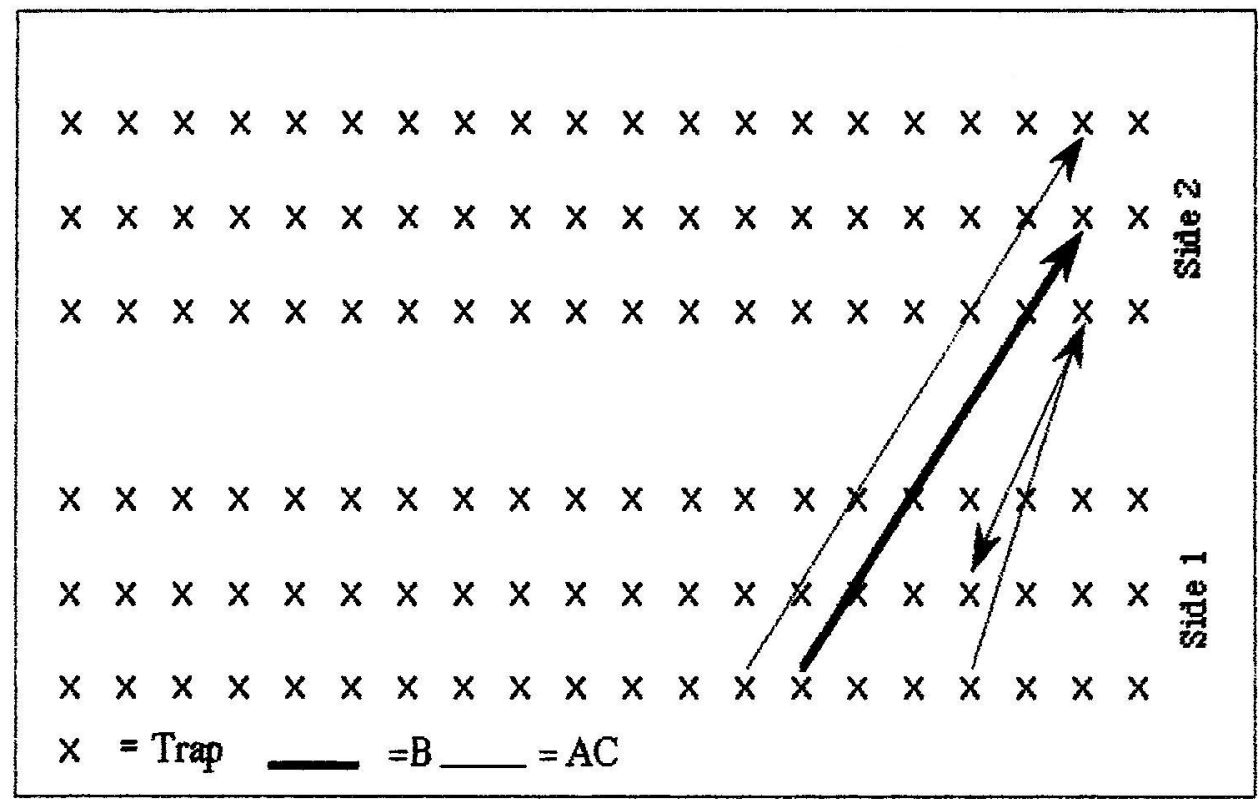

a.

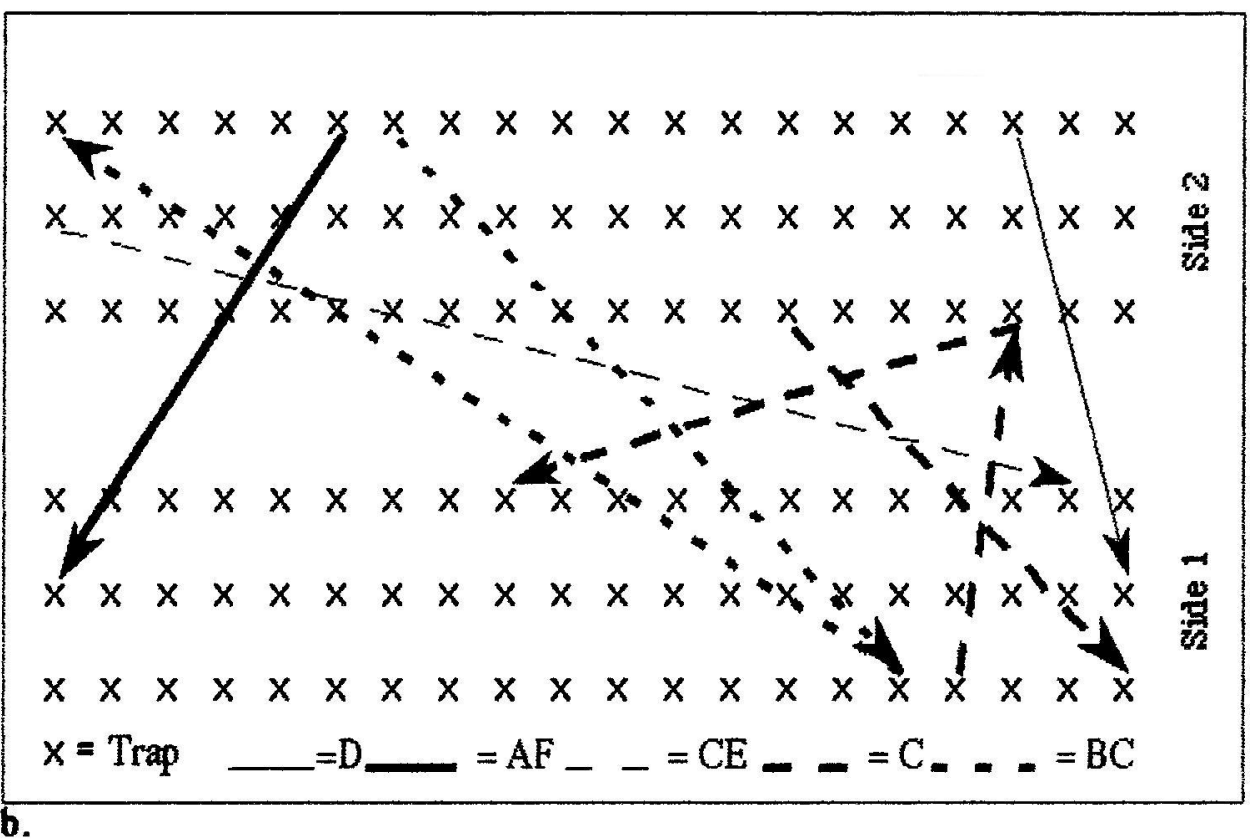

Figure 2. Diagrammatic representation of recorded movements across road at site A by A. sylvaticus (top) and M. glareolus (bottom). 
Unlike site A, crossings at site B were recorded along the length of the trap grids (Fig. 3). Crossings were approximately equal in both directions for both species. $M$. glareolus accounted for $60 \%$ of the animals recorded crossing but only $50 \%$ of the crossings. Males accounted for $80 \%$ of the animals involved in crossing with one animal (A. sylvaticus) accounting for $29 \%$ of the crossings. Two animals crossing at site B were sub-adults (one male and one female $M$. glareolus).

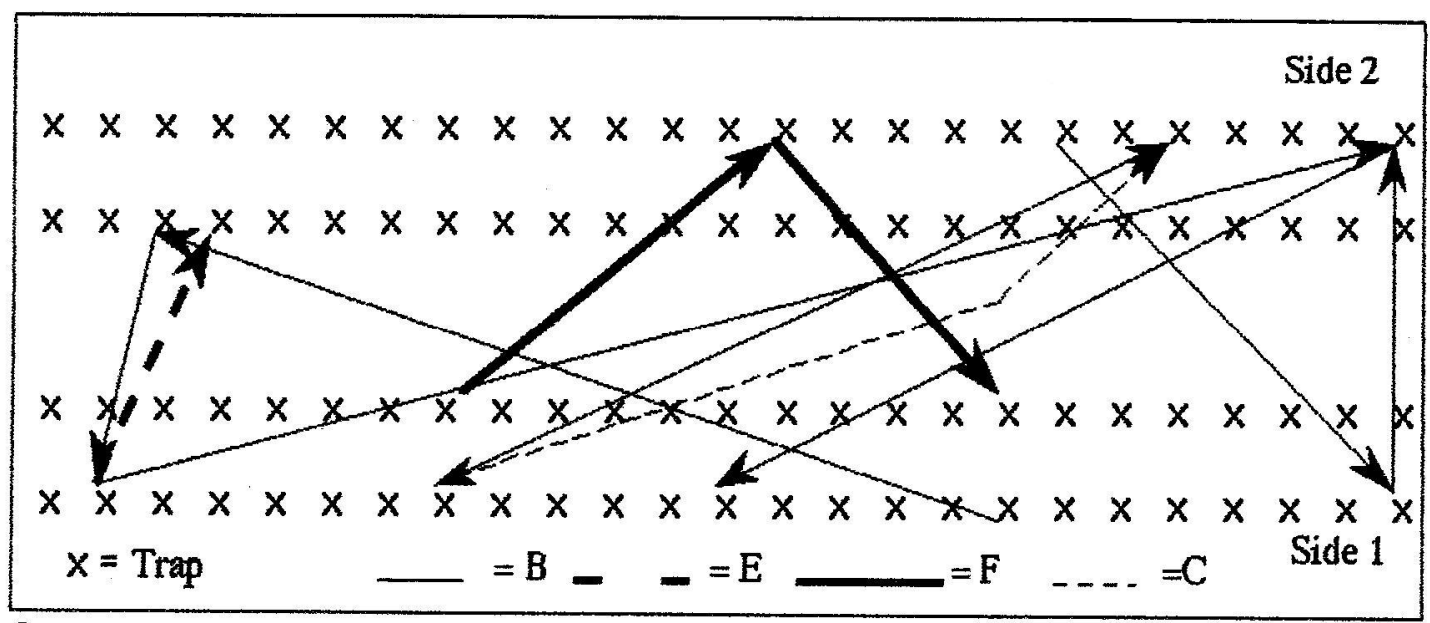

a.

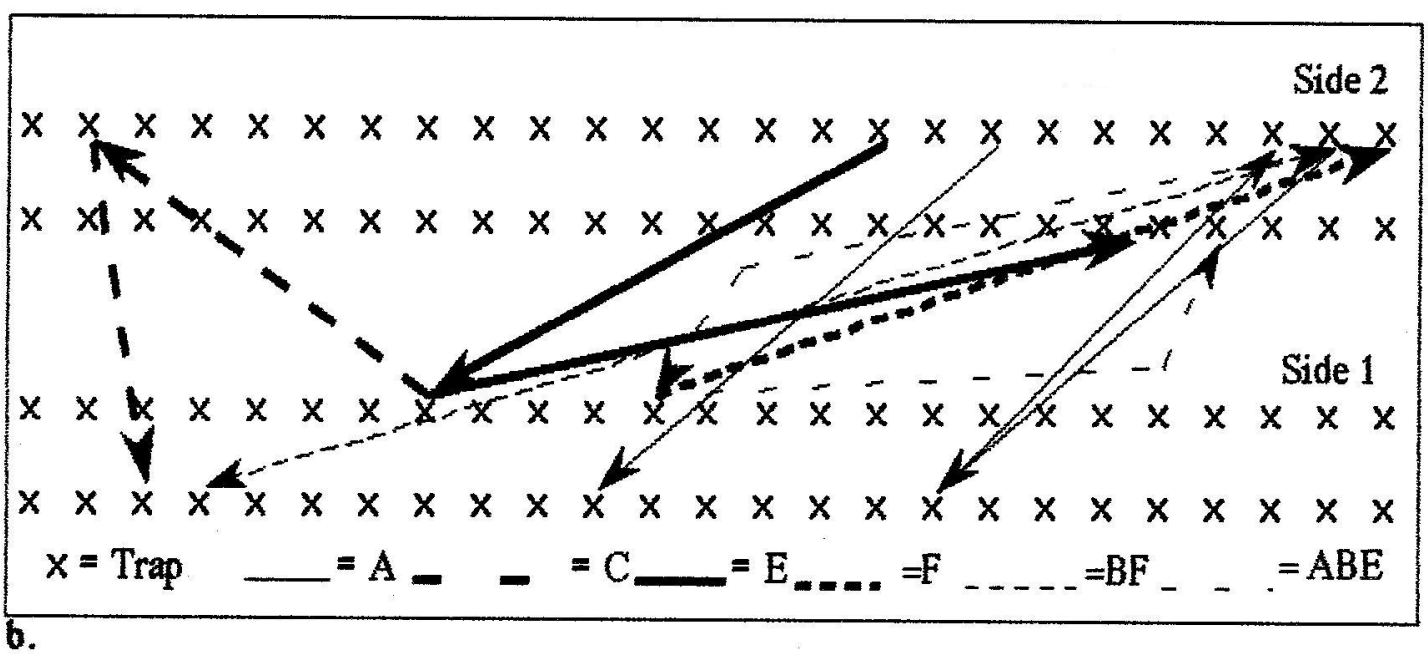

Figure 3. Diagrammatic representation of recorded movements across road at site B by A.sylvaticus (top) and M.glareolus (bottom)

Only a small proportion of the total population made road crossings, $7 \%$ of marked A. sylvaticus and $12 \%$ of marked $M$. glareolus at site A, and at site B comparable figures were $28 \%$ for A. sylvaticus and $22 \%$ for M. glareolus. 
Table 4. Details of all animals involved in recorded road crossings at sites $A$ and $B$

\begin{tabular}{|c|c|c|c|c|c|c|c|}
\hline site & Species & mark & $\operatorname{sex}$ & $\begin{array}{c}\text { Weight } \\
\text { (g) }\end{array}$ & $\begin{array}{l}\text { Breeding } \\
\text { condition }\end{array}$ & $\begin{array}{c}\text { Number } \\
\text { of } \\
\text { crossings } \\
\text { recorded }\end{array}$ & $\begin{array}{l}\text { Total no. } \\
\text { of } \\
\text { captures }\end{array}$ \\
\hline \multirow[t]{7}{*}{ A } & \multirow[t]{2}{*}{ A. Sylvaticus } & $\mathrm{B}$ & $\mathrm{F}$ & 29 & Perforate & 1 & 11 \\
\hline & & $\mathrm{AC}$ & $\mathrm{F}$ & $>30$ & Pregnant & 3 & 5 \\
\hline & \multirow[t]{5}{*}{ M. glareolus } & $\mathrm{D}$ & $\mathrm{F}$ & 25 & Perforate & 1 & 3 \\
\hline & & $\mathrm{AF}$ & $\mathrm{F}$ & 25 & Perforate & 1 & 6 \\
\hline & & $\mathrm{CE}$ & $\mathrm{F}$ & 25 & Perforate & 1 & 8 \\
\hline & & $\mathrm{C}$ & M & 28 & Scrotal & 3 & 13 \\
\hline & & $\mathrm{BC}$ & M & 16 & Abdominal testes & 2 & 6 \\
\hline \multirow[t]{10}{*}{$\mathrm{B}$} & \multirow{4}{*}{ A. Sylvaticus } & $\mathrm{C}$ & $\mathrm{F}$ & 25 & Pregnant & 2 & 9 \\
\hline & & B & M & 27 & Scrotal & 7 & 21 \\
\hline & & $\mathrm{E}$ & M & 22 & Scrotal & 1 & 6 \\
\hline & & $\mathrm{F}$ & M & 23 & Scrotal & 2 & 26 \\
\hline & \multirow[t]{6}{*}{ M. glareolus } & $\mathrm{ABE}$ & $\mathrm{F}$ & 15 & Imperforate & 2 & 6 \\
\hline & & $\mathrm{A}$ & M & 28 & Scrotal & 3 & 18 \\
\hline & & $\mathrm{C}$ & M & 25 & Scrotal & 2 & 11 \\
\hline & & E & M & 14 & Abdominal & 2 & 10 \\
\hline & & $\mathrm{F}$ & $\mathrm{M}$ & 24 & Scrotal & 1 & 5 \\
\hline & & $\mathrm{BF}$ & M & 24 & scrotal & 2 & 4 \\
\hline
\end{tabular}

To investigate whether the breeding condition of the animals affected the type of animal crossing the roads, the number of breeding (scrotal, perforate and pregnant) and non-breeding (abdominal and imperforate) animals recorded (Table 4) as crossing the road was compared to the number of breeding and non-breeding marked animals within the verges, which had been recorded as having travelled distances equal to or greater than the widths of the roads but had not been recorded crossing the road (Fig. 4).

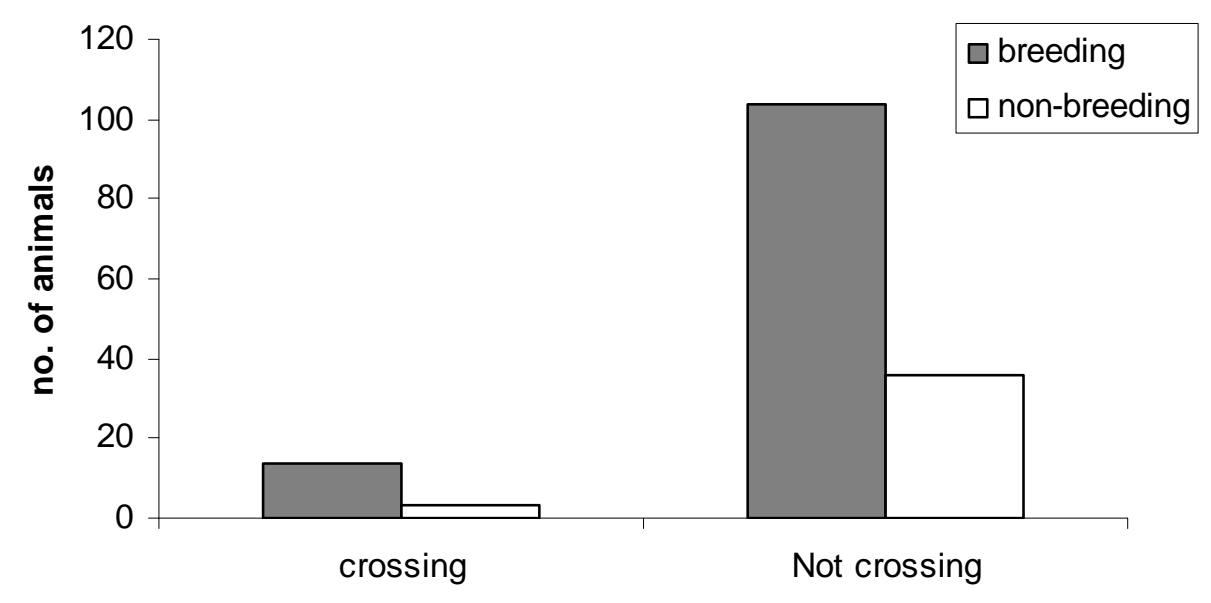

Figure 4. Comparing the numbers and breeding condition of animals recorded crossing the road with those recorded as having travelled distances $\geq$ road width within the verge but not crossing the road

There was no significant difference between the numbers of breeding and nonbreeding animals travelling distances greater than or equal to the width of the road 
within the verge, and those crossing the road $\left(\chi^{2}=-0.53\right.$, d.f. $=1$, right tail $\left.p=0.46\right)$. This suggests that breeding condition is not a significant factor affecting whether animals cross the road or not.

Forty nine animals were translocated from their capture site to the opposite side of the road, 33 at site A and 16 at site B, of which 11 (33\%) and $5(31 \%)$ respectively were recorded as returning to the side of the road where they were originally captured (Fig. 5).

\section{site A}

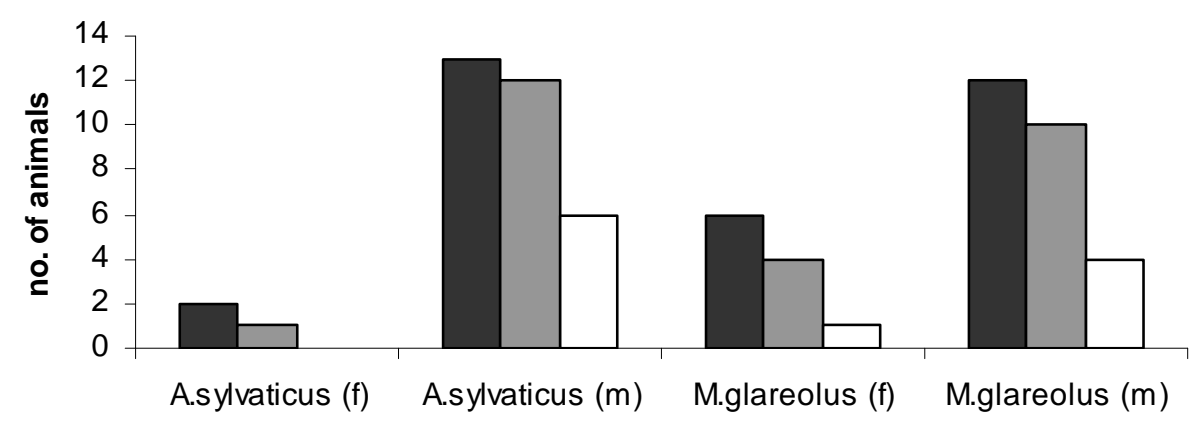

site $B$

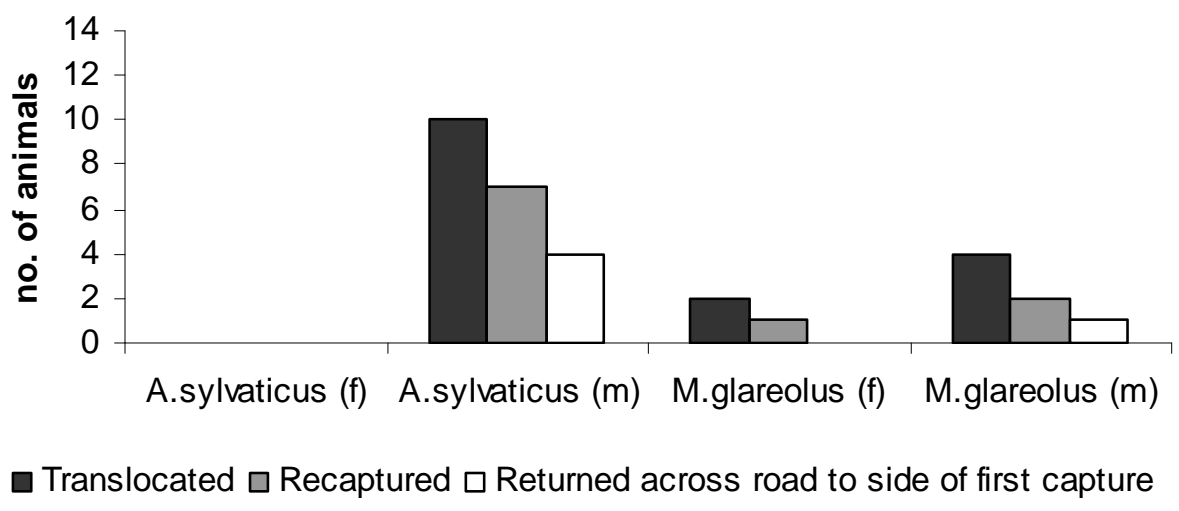

Figure 5. Numbers of animals translocated, recaptured, and crossing the road to the side from which they originated, broken down by species and sex

Overall $37(75.5 \%)$ translocated animals were recaptured, but only $16(43.2 \%)$ of those recaptured had crossed the road to return to the side on which they had been captured.

At site $\mathrm{A}$ the difference between the numbers of $A$. sylvaticus and $M$. glareolus crossing the road to their original side was significant $\left(\chi^{2}=5.25, \mathrm{df}=1, p=0.022\right)$, but no such difference between the two species was found at site $\mathrm{B}\left(\chi^{2}=0.476, \mathrm{df}=1, p=0.49\right)$. Similarly, when the data for both species were pooled there was no significant difference between sites $\mathrm{A}$ and $\mathrm{B}$ in the total number of animals crossing back $\left(\chi^{2}=0.10\right.$, $\mathrm{df}=1, p=0.92$ ), suggesting that greater road width at site $\mathrm{A}$ was not a disincentive to crossing. 


\section{Discussion}

This study was designed to investigate whether small rural roads act as a barrier to the free movement of small mammals. Therefore as far as possible factors that may have influenced movements were minimised. By having similar and adequate vegetation on both sides of the road, and choosing roads with low volumes of traffic, little pedestrian use and avoiding periods of verge management, it was possible to minimise the effects of territory, food supply and vehicle disturbance.

A significant difference in the number of $A$. sylvaticus found either side of the road at site A suggested that differences existed between these verges. This might have been due to the vegetation, but the only statistically significant vegetational difference was found to be at site B (possibly because side 2 had a raised bank with a slope of 1:2). However, the plant data only allowed for species abundance and did not take into account the amount of each species that was present, or the three dimensional area they produced. Observations at site A suggest that, especially for Rubus fruticosa, this three dimensional area was greater $(\mathrm{c} 40 \%)$ on side 2 than side 1 . The verge on side 1 also differed in that a small $(15 \times 6 \mathrm{~m})$ but densely wooded area created space with little ground cover. These differences between the verges may account for the small number of $A$. sylvaticus marked in this verge (side 1) and the fact that only one observed crossing for this species was towards this side.

No other significant differences in the numbers of animals marked on either side of the road were found, indicating that for $M$. glareolus at site A and for both species at site $\mathrm{B}$, both verges at each site were capable of supplying the needs of the resident small mammal populations. Therefore unless the population density reached levels that one side of the road could no longer support, any crossing movements recorded were likely to be normal and possibly regular events. These are probably more important in terms of continuous gene flow than the passing through of migrating sub-adults.

All animals involved in the study were capable of travelling distances equivalent to or greater than the width of the roads, yet there was a very highly significant difference between the number of animals travelling these distances within the verge and the number recorded crossing the roads, indicating that the road is to some extent an obstacle. As no significant difference in movements was found between A. sylvaticus and $M$. glareolus their behaviour in respect of the road is evidently similar and the species will only be considered separately where necessary.

The number of animals that crossed the road was very small $(5.6 \%$ of all marked animals at site A and $10.4 \%$ at site B). As the study was carried out during the breeding season the majority of road crossing was expected to involve sub-adult animals dispersing in search of territory and would probably be one-way movements, but this was not supported by the data. At site A the majority (57\%) of animals crossing the road were perforate females making a single crossing, and the remaining $43 \%$ consisted of one pregnant female and two males, only one of which was in breeding condition. All three made multiple crossings. No perforate females were recorded crossing at site B although $80 \%$ were adults and the remaining $20 \%$ were non-breeding sub-adults. With the exception of two scrotal males, all those that crossed the road were recorded making multiple crossings, yet no significant difference in the distance travelled by adults and sub adults for either species was found. The trapping dominance of adult animals may have been due to the inherent problems of live trapping with single capture traps such as the Longworth, which have been shown to be biased towards adults (Montgomery, 1979). Approximately $80 \%$ of trapped animals at both sites, and of both species were 
adults conforming to other studies such as Gliwicz (1970) and Jensen (1975) which have shown that trappability is highest in mature animals. Additionally the majority of the crossings recorded were made by $M$. glareolus, which is surprising since Apodemus is generally considered to be the more wide-ranging species. Our results show that individuals of both species were able to cross the roads at both sites, yet few were recorded actually doing so. The fact that at both sites, and for both species, crossings did occur confirms previous findings that road surface is not a critical factor, (Oxley et al., 1974). Traffic may also be discounted due to low volume and the high occurrence of animals in traps close to the road edge at site A, where the highest volume of traffic was recorded. "Road clearance", an area devoid of refuges and cover, is suggested as the most important inhibiting factor (Bider, 1968; Oxley et al., 1974). Data from the present study also suggest that it is the lack of cover that inhibits crossings, in that both species seem to prefer dense cover. This is indicated by the difference in numbers of animals captured in the inner and outer lines at site B, where cover in the outer line was light and patchy, compared to site A where cover was dense for all trap lines.

The crossing routes shown in figures 2 and 3 are probably unrealistic, as it is more likely that animals would use the shortest route possible. However the fact that crossings originate from both sides of the road, and the animals involved do not appear to head for one specific area, indicates that crossings are not for a single specific resource and similar results would be likely to occur at any point along the road.

A. sylvaticus are territorial during the breeding season (Flowerdew, 1991) and have a magnetic sense of direction which allows them to find their home territory (Mather and Baker, 1981). Adult M. glareolus are described as living within fixed home ranges to which they return when displaced (Karlsson, 1984). Therefore if translocated it might be expected that the majority, if not all the animals, would return. However, although three-quarters of our translocated animals were recaptured, only $43.2 \%$ were returnees, with $M$. glareolus producing fewer returnees than A. sylvaticus. This could, indicate that the road is a total barrier to part of the population as proposed by Bakowski and Kozakiewicz (1988), even when the instinct to return is strong. Mazurciewicz characterised $M$. glareolus as being highly sedentary, the reason suggested by Bakowski and Kozakiewicz (1988) for the low occurrence of recorded road crossings. However in tests with no barrier both Bovet (1978) (with A. sylvaticus) and Karlsson (1984) (with M. glareolus) found that about $30 \%$ of animals failed to return "home".

The time of day when animals were translocated may also have affected their behaviour. Both Karlsson (1984) and Bovet (1960) suggest that sunlight disorientates bank voles, although this conflicts with the findings of another study (Mather and Baker, 1980) which showed that vision combined with olfaction were the major senses involved in navigation of up to $80 \mathrm{~m}$ distance for both A. sylvaticus and M. glareolus. In the present study $71 \%$ of animals were translocated between 06.00 and 07.00 and the remaining $29 \%$ between 18.00 and 19.00 . The time allowed for animals to return is also important. Durup et al. (1973) showed that homing from a distance of 25-30m was accomplished in about 36 hours by $M$. glareolus, and in about 50 hours by A. sylvaticus. Therefore the length of time allowed in the present study for the animals to return may have been insufficient, as $27 \%$ of our animals were translocated only 36 hours before the end of the study. Long distance movements and occasional excursions have been explained as being undertaken by dispersing animals and exploratory ventures out of home ranges. Such movements occur mainly in the reproductive season (Maza et al., 1973), which is when the present study was conducted. This could explain both the 
single (dispersal) and double (exploratory) crossings, but not, for example, the adult A. sylvaticus at site B recorded crossing seven times. This number of crossings by a single male may represent searching for suitable females, but, out of 19 adult males, this was the only one recorded making multiple road crossings.

Andrzejewski and Babinskawerka (1986) proposed that for M. glareolus territories are much larger than many suggest. If so, it may be that some territories included parts of the opposite verge. This could explain multiple crossings by adult animals and indicate that the road is not perceived as a barrier. This has been discussed in the context of home ranges by other authors (Szacki et al., 1993; Vasilev et al. 1996) and may explain why only part of a population is involved in crossing roads.

It is important to remember that studies such as the present one are limited and that there will be many gaps in the information gained. For example the distances travelled were calculated from two consecutive captures, but this may not be a true representation. The journey may have been cut short by the trap and the actual route taken by the animal is unknown. Many consecutive trappings were 48 hours apart or longer, and it is not known where the animal travelled during this time. If the animal crossed the road other than in search of food there is little incentive for it to enter a trap. Crossings may also be more frequent than indicated by trapping. During a three-hour study at site B starting from dusk, four crossings were registered by use of an infra-red night scope. It was not possible to identify how many individuals were involved by this method, but it does suggest that crossings may be more common than shown by trapping.

The use of single-entry traps has many limitations and the data generated from their use suffers from pseudo-replication. However this study has shown that rural roads of $6 \mathrm{~m}$ or less in width are not a total barrier, but are perhaps treated more as a boundary, which is crossed by members of all categories of the two species studied. Although a difference in the number of crossings was recorded between site $\mathrm{A}$ and site $\mathrm{B}$ suggesting that the width of the road made a difference, it is thought that this is more likely to result from the difference in population levels of A. sylvaticus found between side 1 and side 2 at site A. Nevertheless it is clear that small mammals appear reluctant to cross roads, even narrow ones like these.

Acknowledgements. We would like to thank the Colin Reid Countryside Trust for their financial support of this study, and Dr. P. Bright for his comments.

\section{REFERENCES}

[1] Adams, L.W., Geiss, A.D. (1983): Effects of roads on small mammals. - Journal of Applied Ecology 20: 403-415.

[2] Andrzejewski, R., Babinskawerka, J. (1986): Bank Vole Populations - Are Their Densities Really High and Individual Home Range Small. - Acta Theriologica 31(2741): 409-422.

[3] Bakowski, C., Kozakiewicz, M. (1988): The Effect of Forest Road on Bank Vole and Yellow-Necked Mouse-Populations. - Acta Theriologica 33(12-25): 345-353.

[4] Bider, J.R. (1968): Animal activity in uncontrolled terrestrial communities as determined by a sand transect technique. - Ecological Monographs 38: 269-308. 
[5] Bovet, J. (1978): Homing in wild myomorph rodents: current problems. - In: SchmidtKoenig, K., Keeton, W.T. (eds), Animal Migration, Navigation and Homing, Springer-Verlag, Berlin, Heidelberg, New York, pp. 3-24.

[6] Bovet, V.J. (1960): Experimentelle Untersuchungen über das Heimfindevermögen von Mäusen. - Z. Tierpsychol. 17: 728-755.

[7] Dept.forTransport (2011): Road statistics 2009: traffic, speeds and congestion, viewed 10 February 2011 - http://www.dft.gov.uk/pgr/statistics/datatablespublications/roadstraffic/speedscongestion/roadstatstsc/roadstats09tsc.

[8] Durup, M., Saint-Girons, M.C., Fabrigoule, C., Durup, H. (1973): Data concerning the return to the burrow in the field mouse Apodemus sylvaticus and the reddish meadow mouse Clethrionomys glareolus. - Mammalia 37: 34-55.

[9] Fischer, J., Lindenmayer, D.B. (2000): An assessment of the published results of animal relocations. - Biological Conservation 96(1): 1-11.

[10] Flowerdew, J.R. (1991): The wood mouse. - In: Corbet, G.B., Harris, S. (eds), The Handbook of British Mammals, Blackwell Scientific Publications, Oxford, pp. 220-9.

[11] Gerlach, G., Musolf, K. (2000): Fragmentation of landscape as a cause for genetic subdivision in bank voles. - Conservation Biology 14(4): 1066-1074.

[12] Gliwicz, J. (1970): Relation between trappability and age of individuals in a population of the bank vole. - Acta Theriologica 15: 15-23.

[13] Goodman, D. (1987): The demography of chance extinction. - In: Soule, M.E. (ed.) Viable Populations for Conservation, Cambridge University Press, New York.

[14] Gurnell, J., Flowerdew, J.R. (1995): Live trapping small mammals: a practical guide, Mammal Society Occasional Publications 3. - The Mammal Society, London.

[15] Hanski, I. (1999): Metapopulation Ecology. - Oxford Series in Ecology and Evolution, Oxford University Press, Oxford.

[16] Holderegger, R., Di Giulio, M. (2010): The genetic effects of roads: A review of empirical evidence. - Basic and Applied Ecology 11(6): 522-531.

[17] Jensen, T.S. (1975): Trappability of various functional groups of the forest rodents Clethrionomys glareolus and Apodemus flavicollis, and its application in density estimation. - Oikos 26: 196-204.

[18] Karlsson, A.F. (1984): Age-differential homing tendencies in displaced bank voles Clethrionomys glareolus. - Animal Behaviour 32: 515-519.

[19] Lande, R. (1993): Risks of Population Extinction from Demographic and Environmental Stochasticity and Random Catastrophes. - American Naturalist 142(6): 911-927.

[20] Mader, H.J. (1984): Animal Habitat Isolation by Roads and Agricultural Fields. Biological Conservation 29, no. 1, pp. 81-96.

[21] Mansergh, I.M., Scotts, D.J. (1989): Habitat continuity and social organisation of the mountain pygmy-possum restored by tunnel. - Journal of Wildlife Management 53: 701-707.

[22] Mather, J.G., Baker, R.R. (1980): A demonstration of navigation by small rodents using an orientation cage. - Nature 284: 259-262.

[23] Mather, J.G., Baker, R.R. (1981): Magnetic Sense of Direction in Woodmice for Route-Based Navigation. - Nature 291(5811): 152-155.

[24] Maza, B.G., French, N.R., Aschwanden, A.P. (1973): Home range dynamics in a population of heteromyid rodents. - Journal of Mammalogy 54: 405-425.

[25] Montgomery, W.I. (1979): An examination of interspecific, sexual and individual biases affecting rodent captures in Long- worth traps. - Acta Theriologica 24: 35-45.

[26] Oxley, D.J., Fenton, M.B., Carmody, G.R. (1974): The effects of roads on populations of small mammals. - Journal of Applied Ecology 11: 51-59.

[27] Sikorski, M.D., Bernstein, A.D. (1984): Geographical and intrapopulation divergence in Clethrionomys glareolus. - Acta Theriologica 29: 219-230. 
[28] Szacki, J., Babinskawerka, J., Liro, A. (1993): The Influence of Landscape Spatial Structure on Small Mammal Movements. - Acta Theriologica 38(2): 113-123.

[29] Vasilev, A.G., Vasileva, I.A., Lukyanov, O.A., Lukyanova, L.E. (1996): Comparison of migratory and resident individuals of the bank vole by a complex of numeric traits. - Russian Journal of Ecology 27(5): 355-360.

[30] Way, J.M. (1977): Roadside verges and conservation in Britain: a review. - Biological Conservation 12: 65-74. 